комплекс находится в стадии доработки. Часть его уже используется в учебном процессе, другая часть - в стадии апробации.

Так, с 10 декабря 2020 г. по 31 декабря 2022 г. по Постановлению Правительства РФ от 07.12.2020 N 2040 «О проведении эксперимента по внедрению цифровой образовательной среды» на территории четырнадцати субъектов РФ проводится эксперимент по внедрению цифровой образовательной среды в сфере общего образования, среднего профессионального образования и соответствующего дополнительного профессионального образования, профессионального обучения, дополнительного образования детей и взрослых. Очевидно, что интеграция цифровых решений в деятельность образовательной организации - это не возвращение к дистанту, а дополнительный механизм реализации образовательной деятельности и важнейшая задача в рамках реализации государственной стратегии цифровизации российской экономики. [3]. В вузах такая модель обучения используется наряду с традиционной.

$$
* * *
$$

1. Вергелес, Г.И. Дистанционное обучение в начальной школе: за и против / Г.И. Вергелес, О.А. Граничина//Начальная школа - №2-2021 - 3-6 - текст непосредственный

2. Гончарова, 3.Г. Дистанционное обучение как инновационная модель преподавания математики в высшей - текст электронный / З.Г.Гончарова URL: https://cyberleninka.ru/article/n/distantsionnoeobuchenie-kak-innovatsionnaya-model-prepodavaniya-matematiki-v-vysshey-shkole

3. Савичева, Е. В. Цифровизация школы - это возвращение дистанта или рывок в будущее?- текст электронный /E.B. Савичева - URL:https://pravo-prosv.ru/files/pегиональный.pptx

\title{
Петренко А.А. \\ Образовательные тренды как ориентир развития компетенций современного учителя
}

ФГБОУ ВО РГУ имени С.А. Есенина (Россия, Рязань)

doi: 10.18411/scienceconf-11-2021-14

\section{Аннотация}

В статье обосновываются современные требования к развитию профессиональных компетенций учителя на основе анализа научных педагогических исследований. Представлена технология, содержание методической деятельности по развитию компетенций педагогов в школе. Рассматриваются образовательные тренды как ориентир выбора содержания методической работы, отвечающего потребностям современного общества: тенденции развития образовательного процесса.

Ключевые слова: учитель, компетентный учитель, компетентность, методическая работа, содержание методической деятельности, образовательные тренды, тенденции развития образовательного процесса, командообразование.

\section{Abstract}

The article justifies the modern requirements for the development of teacher's professional competencies based on the analysis of scientific pedagogical research, the regulatory framework of state educational policy in Russia. Technology, content of methodological activities on development of competencies of teachers in school are presented. Educational trends are considered as a guideline for choosing the content and organization of methodological work in a school that meets the needs of modern society: trends in the development of modern teacher education.

Keywords: teacher, competent teacher, competence, methodical work, content of methodical activity, educational trends, trends of development of educational process, team building. 
Учитель - главный субъект образовательного процесса, от него зависит качество подготовки обучающихся и управления их саморазвитием, уровень организации учебно-воспитательного процесса, творческая атмосфера в школе. Профессиональное становление и развитие учителя формируется на различных этапах его подготовки: допрофессиональном (школа), профессиональном (вуз), дополнительно профессиональном (институты повышения квалификации (ИПК)), а также выделяется этап между вузом и ИПК - практический - в рамках методической работы в школе. Именно на данном этапе осуществляется апробация новых знаний, полученных в вузе и ИПК, «вживление» нового в реальную педагогическую практику. Ценность этапа методической подготовки учителя в школе к внедрению различных инновационных идей, норм, требований, безусловно, высока. В современных условиях повышаются требования к учителю именно с позиции формирования его практических умений и навыков обучать «по-новому» с учетом изменений, которые происходят в обществе. Общество диктует новые требования к учителю, которые в последнее время приобрели достаточно конкретное своё выражение - учитель должен быть компетентным. А это означает, что он не просто носитель новых, самых современных знаний, умений и навыков, и не просто хороший исполнитель «чужих», но очень модных технологий и методик. Современный компетентный учитель - это, прежде всего, учитель, обладающий способностями решать проблемы и задачи в учебной, воспитательной, социально-бытовой, политической и других сферах на основе глубокого знания и понимания основ преподаваемых дисциплин. Кроме того, учитель должен быть готов решать возникающие проблемы в нестандартных/сложных ситуациях. А.К. Маркова утверждает, «профессионально компетентен такой труд учителя, в котором осуществляется на достаточно высоком уровне педагогическая деятельность, педагогическое общение, реализуется личность учителя, в котором достигаются хорошие результаты в обучении и воспитанности учащихся» [3]. В данной трактовке компетентности учителя А.К. Маркова подчёркивает роль не только технологического владения педагогической деятельностью, но и уровень общения учителя, его личностные качества, которые, прежде всего, зависят от его культуры, профессионально-этических качеств.

Исследований в области формирования профессиональных компетенций современного учителя в настоящее время появилось достаточно много: И.С. Зверева, В. В. Вербицкий, А.А. Хуторской, М.М. Поташник и др. Все они могут выступать источниками для педагогического просвещения в рамках методической работы в школе. Однако не только педагогические научные труды раскрывают суть и смысл нового компетентностного подхода в подготовке учителя. Сегодня достаточно чётко и конкретно сформулированы требования к учителю в данной парадигме, и в профессиональном стандарте «Педагог» (2013 г.), и в новой модели аттестации учителя, новых должностях учительской профессии (учитель, старший учитель, ведущий учитель). Так, например, новая модель аттестации учителя предполагает внедрение процедуры объективного исследования компетенций учителя: психологопедагогических, методических, коммуникативных, личностных. Несомненно, будет необходима специальная подготовка учителя к прохождению аттестации, методическое сопровождение его готовности к проявлению всех компетенций на достойном уровне, психологическая помощь в снятии «барьеров», стрессов в данной ситуации.

«В процессе организации методической работы определение ключевых компетентностей осуществляется в контексте идеального образа преподавателя, его профессиональной культуры, с учётом «исходного» и «ожидаемого» уровней развития профессионального потенциала субъекта методической работы» [1]. В этом утверждении И.О. Гордиенко раскрывается методология планирования и организации работы с учителями по формированию компетенций: 
- смоделируй идеальный образ компетентностного учителя своей школы (требуемые качества, способности, необходимые знания, умения, трудовые действия и др.);

— исследуй реальный уровень компетентности (т. е. сопоставь с «ожидаемой» моделью учителя в контексте «идеального образа» (федеральные, региональные, муниципальные требования к его компетенции);

- выяви его несоответствия и спланируй методическое сопровождение по их минимизации или ликвидации.

Изменение целевых установок в подготовке обучающихся как конкурентоспособных, компетентных выпускников со сформированными духовнонравственными ценностями российской отечественной культуры выявили потребность в подготовке компетентностного учителя, способного достичь в своей педагогической деятельности данную цель. В связи с этим при организации методической работы необходимо учитывать новые цели и ценности современного образования относительно личности педагога, его качеств, компетенций, способностей, а также «количественный и качественный состав своих педагогов, особенности содержания методической работы, традиции учебного заведения, сравнительную эффективность различных форм методической работы; меру в использовании тех или иных методов, форм, приёмов методической работы; наличие времени для осуществления намеченной методической работы (возможное сокращение количества мероприятий, перенос по времени и т. д.); материальные и морально-психологические условия, имеющиеся в конкретный момент реальные возможности привлекать педагогических работников к организации методической работы, быть руководителем методического объединения, входить в состав творческой группы и т. д.» [1].

Содержание методической работы по формированию требуемых компетенций учителя формируется на основе следующих источников: нормативные документы, регламентирующие требования к организации методической работы; научнопедагогические, психолого-педагогические исследования по проблемам (в данном случае, формирования компетенций учителя, организации методической работы в данном аспекте; информация о лучшем опыте работы других образовательных организаций страны, региона, муниципалитета; информация о современных тенденциях и трендах развития технологии обучения и обновления содержания образования; анализ результативности качества образования с целью выявления актуальных/типичных для данной школы проблем и затруднений, позволяющие выявить темы методической работы для данного образовательного учреждения, спроектировать работу методических объединений.

Современного учителя в условиях бурного роста инновационных процессов в образовании, изменяющихся реалий общества особенно волнует вопрос «чему и как учить?». Учитель понимает, что для того чтобы работать по-новому, совершенствоваться и развиваться, прежде всего, должен именно он, причём, не только как профессиональный педагог, но и как личность, которая интегрируется в информационное образовательное пространство и способна выбрать эффективные инновационные методики и технологии обучения, быть всегда открыт новым знаниям. Как писал К.Д. Ушинский «Учитель живёт до тех пор, пока учится; как только он перестаёт учиться, в нём умирает учитель» [7].

Попробуем представить более конкретно одно из содержательных полей методической работы - информирование о современных трендах образования, Современные тренды образования являются ориентиром для формирования компетенций учителей. Они (тренды) отвечают на вопрос, чему и как учить детей в контексте уже «случившихся» и предполагаемых/возможных «трендов», используемых сейчас и востребованных в ближайшие два, три года в системе образования. 
Однако следует определить смысл данного термина - «тренд». Что это: дань моде или замена уже устоявшегося термина «тенденция», который более привычен для характеристики каких-либо явлений, тем более, что в переводе с английского «trend»это тенденция.

В отечественной науке понятие «тренд» используется для характеристики востребованных, популярных изменений в ближайшем будущем, которые могут быть, а могут и не реализоваться, подчёркивается его вероятностный характер применения.

Тенденция же указывает на направление, которое состоялось и закрепилось в реальности. Н.Е. Мойсеюк выделил двенадцать тенденций в развитии образования: «гуманизация, гуманитаризация, национальная направленность образования, открытость, перенос акцента с собственно учебной деятельности педагога на продуктивную учебно-познавательную, переход от преимущественно информационных форм к методам, формам и технологиям обучения с использованием элементов проблемности, научного поиска, резервов самостоятельной работы, творческая направленность образовательного процесса, непрерывность образования и ряд других» [4]. По мнению Т.Б. Черепановой «если образовательный тренд можно обозначить как вызывающий интерес инновационный прорыв, своеобразный «модный пробный шар», то образовательная тенденция характеризуется совокупностью выявленных закономерностей, пролонгированных на некоторый более или менее продолжительный период» [8].

Ведущие тренды современного образования выделил Патрик Гриффин (профессор Мельбурнского университета): «В XXI веке акценты смещаются в сторону умения критически мыслить, способности к взаимодействию и коммуникации, творческого подхода к делу» [5].

Данные тренды в современном образовании в качестве целей подготовки подрастающего поколения к жизни еще называют как четыре «К»: «критическое мышление, командообразование, коммуникация и креативность». Именно они способны сформировать компетентностную, конкурентоспособную, целостную личность. Трендовая целевая установка требует поиска новых трендовых подходов к организации образовательного процесса, которые сегодня представлены в следующих 10 позициях [2]:

1. Учить работать на результат: стремление улучшить качество обучения и его результат.

Данный тренд предполагает, что современное образование, прежде всего, должно носит практико-ориентированный характер. Процесс обучения выстраивается в контексте решения профессиональных, жизненных проблем. При этом результативность, качество образования, выражающееся в уровне сформированности ключевых компетенций обучающихся, отвечающих требованиям современного общества, являются главными показателями эффективности системы образования.

2. Конструктивизм, опора на имеющиеся знания, умения и навыки обучаюшцихс и постановка сложных задач с целью развития обучаюшихся.

Данный тренд ориентирован на формирование предметных компетенций через личностный опыт обучающихся, освоение новых знаний в проблемных ситуациях, в активной самостоятельной деятельности обучающихся по «добыванию» новых знаний как способ решения конкретных практических задач (например, в ходе проектной деятельности, при решении учебных проблем и т. д.).

3. Управление знаниями, умение организовать систему сбора, хранения и обмена знаниями, контактировать с другими.

Данный тренд предполагает использование современных информационных возможностей как ресурс создания актуальной и востребованной обучающимися системы использования информации, не только в целях решения собственных учебных 
задач, но и обновления знаний за счёт обмена знаниями с другими пользователями современных систем - контентов информации. Кроме того, это предполагает и развитие способностей к кооперированию с другими обучающимися, педагогами, учёными с целью обогащения знаниями, т. е. способности к общению с носителями более высокого уровня знаний субъектами посредством новых систем обмена информацией, которые будут очень востребованы в ближайшем будущем.

4. Создание системы поддержки качества образования, обеспечивающей её участникам различные уровни доступа к информации тогда, когда это необходимо.

Данный тренд предполагает создание различных систем поддержки проектирования и планирования образовательного процесса, столь необходимой для учителей. Например, возможно создание специальных программ, которые будут формулировать цели и задачи учебной дисциплины, но только после того, как учитель ответит на все вопросы конкретной программы.

5. Технологии e-learning.

Данный тренд очень ярко заявил о себе в период пандемии. Речь идёт о процессе обучения онлайн, когда очное общение с учителем не обязательно. Разумное использование возможностей обучения в режиме онлайн даёт широкие возможности для одарённых или детей с ограниченными возможностями здоровья, имеющих специальные предпочтения в изучении отдельных тем, модулей, курсов, предметов. Речь идёт не о замене учителя компьютерами, а о разумном использовании информационно-коммуникационных технологий, дистанционного обучения.

6. «Обучение в неформальной обстановке» (спонтанные способы получения новых знаний, умений и навыков).

Неформальное общение обучающихся с педагогами (с дискуссиями, обменом информацией в «литературных гостиных», «за чашечкой чая», «встречах при свечах»; спонтанное получение знаний от профессионалов по содержанию учебного предмета, но с практическим его проявлением в реальной жизни) гораздо быстрее и эффективнее формирует осознанное понимание сущности научных явлений, процессов, законов и закономерностей.

7. Facebook $и$ Twitter прочно вошли в нашу жизнь, социальнье медиаблоги, Wiki, подкасты, сочиальныле закладки и даже Yоитиревсё это можно и нужно использовать в обучении. К примеру, блоги хорошо встраиваются в образование как средство обратной связи учителя и ученика. А в Youtube можно сделать и продемонстрировать школьникам нужный урок.

8. Введение в обучение образовательных игр. Речь идёт о создании сложных образовательных игр посредством компьютерных программ, которые имитируют исследуемые процессы (например, физические, химические, биологические явления и др.).

9. Методика преподавания естественных наук реализуема только в реальных проблемных ситуациях.

Возможность использования проектных технологий, проблемного, дистанционного, активного и интерактивного обучения в большей степени будет способствовать формированию прочных компетенций и знаний в области естественнонаучных наук.

10. Мобильное образование, включая мобильные обучающие платформы, а также использование в обучении возможностей планшетов и даже смартфонов(ученик всегда может скачать какой-нибудь курс или отдельный урок и заниматься где угодно и когда угодно).

Однако необходимо понимать, что «немедленное» включение в реализацию всех этих трендов требует серьёзного подхода. 
Как говорит Кейс Терлоу, «любое новшество в образовании, любая новая образовательная методика должны последовательно пройти несколько стадий: анализ, проектирование, развитие, внедрение и оценка. Только такой подход к образованию позволит создать по-настоящему качественное обучение» [2].

Информирование учителей о современных трендах образования позволяет спрогнозировать будущие преобразования и направления совершенствования технологии обучения, подготовить учителя к ним.

Современные тенденции в обновлении подходов к организации образовательного процесса можно представить в следующих положениях.

Изменяется роль учителя: не ментор, а навигатор в обширном информационном поле, «Гид» по источникам и ресурсам новых знаний.

Деятельностный подход к организации обучения обеспечивает осознанность осваиваемых знаний. Поэтому не объём информированности или количество знаний, умений и навыков, а действия, самостоятельная деятельность обучаемых, их субъектная позиция в образовательном процессе обеспечивают прочность и качество образования.

Командообразование, «team-building», технологии группогенезиса - наиболее эффективный способ формирования лидерских качеств личности, её умения работать в команде, выполнять различные роли (от генератора идей до исполнителя). В связи с этим использование в процессе обучения групповых и индивидуальных форм обучения, диалоговых методов общения, проектных и организационно-деятельностных технологий становится особенно востребованным. Люди лучше осваивают новые знания, общаясь друг с другом или решая общие задачи в группах.

Новая философия оценивания носит рефлексивный характер, фиксирующий «точки роста» как ориентир саморазвития и разработки будущих стратегий организации образовательного процесса. В то же время жёсткая стандартизация, внедрение федеральных государственных стандартов требуют ответственного отношения к процессу обучения, как со стороны учителя, так и со стороны ученика, так как, фактически, стандартам следует соответствовать, их достигать, и в этом главная цель системы оценивания.

Учитель - разработчик индивидуальных учебных планов, программ (не случайно в профессиональном стандарте закреплены две обобщённые функции учителя, который должен уметь «проектировать образовательный процесс... и проектировать основные образовательные программы»). Понятия «индивидуальный образовательный маршрут», «индивидуальный план обучения» становятся реалиями современного образования. Для обучающихся обучение по индивидуальным планам позволит не только качественно осваивать предметные знания, но и формировать мотивацию к учению, умения свободно ориентироваться в предметных областях. Предоставляя право конструировать свой собственный план образования, у ученика развиваются его творческие, созидательные способности, обеспечивающие его самоопределение, саморазвитие, самореализацию.

Доступность к образовательным возможностям на протяжении всей жизни. Американский философ А. Тоффлер отмечает, что «быстрое устаревание знаний и увеличение продолжительности жизни - причина того, что навыки, полученные в юности, вряд ли будут актуальны в старости или даже в зрелые годы, поэтому школа должна создать серьёзные предпосылки для пожизненного образовательного процесса» [6]. Развитие средств массовой информации, сети Интернет, дистанционных форм обучения становятся важным источником получения информации, конкурирующим с образовательными организациями, которые обеспечивают принцип доступности её получения, но, к сожалению, не всегда соответствуют принципу качества.

Данный перечень современных тенденций далеко не завершён, поэтому важно всегда отслеживать новые направления развития образования и информировать о них педагогов. 
Содержание методической деятельности в школе определяется не только потребностью информирования педагогов о новых тенденциях и трендах современного образования, но, прежде всего, на основании уровня профессиональной компетентности педагогов,и может быть разработано в соответствии с такими её составляющими, как дидактическая, психолого-педагогическая, методическая, технологическая, коммуникативная.

Примерный перечень тем методической работы по каждой из указанных составляющих профессиональной компетентности педагога представлен в таблице.

Таблиия 1

Темы методической работы по развитию дидактической, психолого-педагогической, методической, технологической и коммуникативной составляющих компетенций

учителя

\begin{tabular}{|c|c|}
\hline $\begin{array}{c}\text { Содержсательные блоки по } \\
\text { подготовке педагога }\end{array}$ & Темы методической работы \\
\hline Дидактический & $\begin{array}{c}\text { «Ведущче педагогические концепции обновления содержания и } \\
\text { технологии обучения в современном образовании», } \\
\text { «Теория развиваюшего обучения: механизмы совершенствования } \\
\text { образовательного процесса», } \\
\text { «Компетентностная парадигма как теоретическая основа } \\
\text { преобразования образовательного процесса», } \\
\text { «Сстемно-деятельностный подход } \\
\text { в теории обучения: достоинства } \\
\text { и недостатки», } \\
\text { «Методология теории обучения в логике требований ФГОС нового } \\
\text { поколения» }\end{array}$ \\
\hline Психолого-педагогический & $\begin{array}{c}\text { «Психолого-педагогическая поддержка старшеклассников при } \\
\text { подготовке } \\
\text { к итоговой аттестации (ЕГЭ и др.)», } \\
\text { «Психолого-педагогическое сопровождение детей с ОВЗ } \\
\text { (ограниченными возможсностями здоровья) в проиессе обучения», } \\
\text { «Инклюзивное образование: проблемы, поиски, передовой опьыт } \\
\text { реализации», } \\
\text { «Психолого-педагогическая поддержка учителя в проиессе } \\
\text { подготовки к новой модели аттестачии» }\end{array}$ \\
\hline Методический & $\begin{array}{c}\text { «Методика модульно-рейтингового обучения в школе: за и } \\
\text { против», } \\
\text { «Методика преподавания предмета } \\
\text { в аспекте современных требований ФГОС нового поколения», } \\
\text { «Интерактивные методы обучения } \\
\text { в образовательном прочессе: } \\
\text { опыт педагогов школы», } \\
\text { «Инновационнье методы, формы, приёмы и средства обучения», } \\
\text { «Профессиональная компетентность учителя как основа } \\
\text { формирования ключевых компетеничй обучающчися» }\end{array}$ \\
\hline Технологический & $\begin{array}{l}\text { «Проектные технологии в образовательном процессе: проблемы, } \\
\text { лучший опьт», } \\
\text { «Развиваюшиеся технологии организации современного урока», } \\
\text { «Технология управления образовательным процессом в контексте } \\
\text { требований ФГОС нового поколения», } \\
\text { «Современные образовательные технологии» }\end{array}$ \\
\hline Коммуникативньй & $\begin{array}{c}\text { «Технология командообразования } \\
\text { как эффективный механизм управления классом», } \\
\text { «Этико-психологические особенности делового общения в } \\
\text { педагогическом коллективе», } \\
\text { «Культура педагогической речи», } \\
\text { «Нормы общения с различными участниками образовательных } \\
\text { отношений: учениками, их родителями, законными } \\
\text { представителями обучающихся и др.» }\end{array}$ \\
\hline
\end{tabular}


Таким образом, направления содержания методической работы в школе выявляются, прежде всего, из анализа уровня сформированности профессиональнопедагогической компетентности учителя, его образовательных «дефицитов», информационных запросов, а также составляющих его компетентности в области методики обучения (общей и частной), теории и практики воспитания с учётом современных явлений в обществе, психологии и педагогики, общей культуры учителя (этико-педагогической культуры), освоения новых технологий обучения, современных трендов и тенденций развития современного образования.

Актуализация современного содержания методической работы в аспекте новых трендов и тенденций развития образования предполагает их взаимосвязь, взаимодополнение, сбалансированность развития, что в свою очередь, обеспечит профессиональное развитие компетенций современного учителя.

1. Гордиенко И.В. Организация и управление методической работой в системе среднего профессионального образования : учеб.-методич. пособие / И.В. Гордиенко Ю.М. Мельник. Белгород: ОГАОУ ДПО «БелИРО», 2019. - 144 с

2. Десять трендов современного образования. [электронный ресурс] - Режим доступа: https://www.hse.ru/news/science/63841790.html

3. Маркова А.К. Психология профессионализма / А.К. Маркова. - М. : Знание, 2006. - 144 с

4. Мойсеюк Н.И. Педагогика : учеб. пособие для студентов высших учебных заведений / Н.И. Мойсеюк. - 5-е изд., доп. и перераб. - Киев : Саммит-книга, 2007. - 655 с.

5. Навыки XXI века: HP-Portal (HP - Сообщество и публикация). [электронный ресурс] - Режим доступа:https://hr-portal.ru/article/navyki-xxi-veka-novaya-realnost-v-obrazovanii

6. Тоффлер Ф. Футурошок / пер.с англ. / Ф. Тоффлер - СПб, 1997 -464 с.

7. Ушинский К.Д. Избранные труды. В 4 книгах. Книга 1. Проблемы педагогики /К.Д. Ушинский. - М.: Дрофа, 2005. - 640 с.

8. Черепанова Т.Б. Тренды и тенденции современной образовательной практики //Гуманитарные науки. 2019 №2 (23) C.139-141

\section{Селиверстова Е.Н.}

Новые грани в понимании сущности современного школьного обучения

Владимирский государственный университет (Россия, Владимир)

doi: 10.18411/scienceconf-11-2021-15

\section{Аннотация}

На основе анализа инновационной образовательной практики автором предпринята попытка выявления тенденций, отражающих обновление подходов к пониманию сущностных характеристик современного обучения в сравнении с классическими подходами. Внимание сосредоточено на раскрытии специфики познавательной деятельности обучающихся, реализующейся в современной практике обучения в учебном, игровом и проектном форматах. Это позволило сделать вывод о накоплении массива эмпирических данных, создающих основу для раскрытия новых сторон сущности обучения, отличных только от его учебно-познавательного предназначения.

Ключевые слова: современное обучение, сущность обучения, учебнопознавательная деятельность, игровая деятельность в обучении, проектная деятельность в обучении.

\section{Abstract}

Based on the analysis of innovative educational practices, the author attempts to identify trends that reflect the updating of approaches to understanding the modern education essential characteristics in comparison with classical approaches. Attention is focused on identifying the specifics of students' cognitive activity, which is implemented in modern 